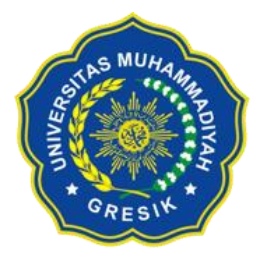

\title{
MATRIK
}

Jurnal Manajemen dan Teknik Industri-Produksi

Journal homepage: http://www.journal.umg.ac.id/index.php/matriks

\section{Perancangan Bak Penampung Bobin di PT. Iskandar Indah Printing Textile Untuk Mengurangi Risiko Postur Kerja}

\section{Cyntia Nathania ${ }^{1}$, Irwan Iftadi ${ }^{2}$, Rahmaniyah Dwi Astuti ${ }^{3}$}

Program Studi Teknik Industri, Fakultas Teknik, Universitas Sebelas Maret

Jalan Ir. Sutami no. 36A, Surakarta, Jawa Tengah, Indonesia nathania.cyntia@gmail.com ${ }^{1}, \underline{\text { iftadi@gmail.com }}{ }^{2}, \underline{\text { niyah22@gmail.com }}^{3}$

\begin{tabular}{l}
\hline INFO ARTIKEL \\
\hline $\begin{array}{l}\text { doi: } \mathbf{1 0 . 3 5 0 5 8 7 / M a t r i k} \\
\text { v18i2.589 }\end{array}$ \\
\hline Jejak Artikel: \\
Upload artikel \\
16 Januari 2020 \\
Revisi oleh reviewer \\
19 Maret 2020 \\
Publish \\
30 Maret 2020 \\
\hline
\end{tabular}

Kata Kunci :

REBA, Ulrich, tekstil, pallet

\section{ABSTRAK}

PT. Iskandar Indah Printing Textile adalah salah satu perusahaan tekstil yang mengolah bahan baku benang menjadi kain mentah (grey) yang kemudian meningkatkan jenis produksi berupa kain printing. Berdasarkan hasil observasi awal, diperoleh dugaan sementara bahwa pada stasiun palet terdapat postur kerja yang tidak ergonomis karena tidak menggunakan alat bantu. Penelitian ini bertujuan mengurangi tingkat risiko postur kerja tersebut dengan mengusulkan rancangan perbaikan alat bantu. Analisis level risiko postur dilakukan dengan menggunakan metode REBA, sehingga diperoleh aktivitas kerja yang memiliki nilai tertinggi yaitu mengambil bobin pada mesin palet. Kemudian dilakukan perancangan alat bantu menggunakan proses pengembangan produk Ulrich dan Eppinger yang menghasilkan tiga alternatif konsep desain. Dari ketiga alternatif tersebut kemudian dipilih satu desain terbaik berdasarkan kriteria seleksi yaitu desain konsep kedua. Bak penampung yang terpilih adalah bak yang memiliki sistem penggerak manual menggunakan handling tangan, mekanisme berupa path linkage, serta ketinggian yang telah disesuaikan dengan mesin palet. 


\section{Pendahuluan}

Industri tekstil merupakan salah satu industri yang diprioritaskan untuk dikembangkan karena memiliki peran penting dalam perekonomian nasional yaitu sebagai penyumbang devisa negara, dan dapat memenuhi kebutuhan sandang nasional, serta memberi lapangan pekerjaan bagi masyarakat(Kementrian Perindustrian Republik Indonesia, 2017).

PT. Iskandar Indah Printing Textile merupakan salah satu perusahaan yang bergerak dalam bidang tekstil di Kota Surakarta. Perusahaan ini berlokasi di jalan Pakel No. 11 Kelurahan Kerten Kecamatan Laweyan, Kota Surakarta mengolah bahan baku benang menjadi kain mentah grey. Departemen weaving terdiri dari enam stasiun, yaitu stasiun warping, stasiun sheising, stasiun recing, stasiun palet, stasiun weaving, dan stasiun finishing.

Industri tekstil tidak bisa lepas dari Kesehatan dan Keselamatan Kerja (K3) sebagai satu syarat untuk meningkatkan dan menjamin kesehatan pekerja. Dalam UndangUndang Nomor 23 tahun 1992 tentang Kesehatan, pasal 23 menyatakan bahwa upaya K3 harus diselenggarakan disemua tempat kerja, khususnya tempat kerja yang mempunyai risiko bahaya kesehatan (Yuwono\&Yuamita, 2015). Secara umum pencapaian keselamatan dan kesehatan kerja sangat berkaitan dengan peran ergonomi, karena ergonomi berkaitan dengan orang yang bekerja, selain dalam rangka efektivitas dan efisiensi kerja (Sedarmayanti, 1996). Ergonomi adalah salah satu bagian dari ilmu kesehatan masyarakat yang berusaha untuk menyerasikan antara faktor manusia, faktor pekerjaan dan faktor lingkungan. Dengan bekerja secara ergonomis maka diperoleh rasa nyaman dalam bekerja, dihindari kelelahan, dihindari gerakan dan upaya yang tidak perlu serta upaya melaksanakan pekerjaan menjadi sekecilkecilnya dengan hasil yang sebesar-besarnya (Soedirman, 1989).

Salah satu penyebab utama gangguan otot rangka adalah postur janggal (awkward posture). Postur janggal adalah posisi tubuh yang menyimpang secara signifikan terhadap posisi normal saat melakukan pekerjaan. Bekerja dengan posisi janggal meningkatkan jumlah energi yang dibutuhkan untuk bekerja, menyebabkan kondisi dimana perpindahan tenaga dari otot ke jaringan rangka tidak efisien sehingga mudah menimbulkan lelah (Kurnianto\&Mulyono, 2014). Masalah lain yang dapat ditimbulkan adalah seperti low back pain atau Musculoskeletal Disorder (MSDs) (Novianti\&Tanjung, 2016).

Sebagian proses produksi pada departemen weaving PT. Iskandar Indah Printing Textile masih menggunakan manual material handling $(\mathrm{MMH})$. Pekerjaan penanganan material secara manual (Manual Material Handling) yang terdiri dari mengangkat, menurunkan, mendorong, menarik dan membawa merupakan sumber utama komplain karyawan di industri (Ayoub \& Dempsey, 1999). Akibat yang ditimbulkan dari aktivitas MMH yang tidak benar salah satunya adalah keluhan muskoloskeletal (Muslimah,dkk., 2006). Namun, pada kenyataannya MMH juga memiliki banyak keuntungan, yaitu : (1) Tidak semua material bisa dipindahkan menggunakan mesin, (2) material ringan akan lebih murah menggunakan tenaga manusia, dan (3) fleksibel dalam gerakan (Astuti\&Iftadi, 2016).

Penelitian ini bertujuan mengurangi risiko postur kerja, serta memberi usulan perbaikan bagi alat bantu.

\section{MetodologiPenelitian}

Pada bagian ini menjelaskan langkah dalam melakukan penelitian, dari tahap identifikasi awal, perancangan alat bantu, hingga tahap kesimpulan. Flowchart metodologi penelitian dapat dilihat pada Gambar 1. 


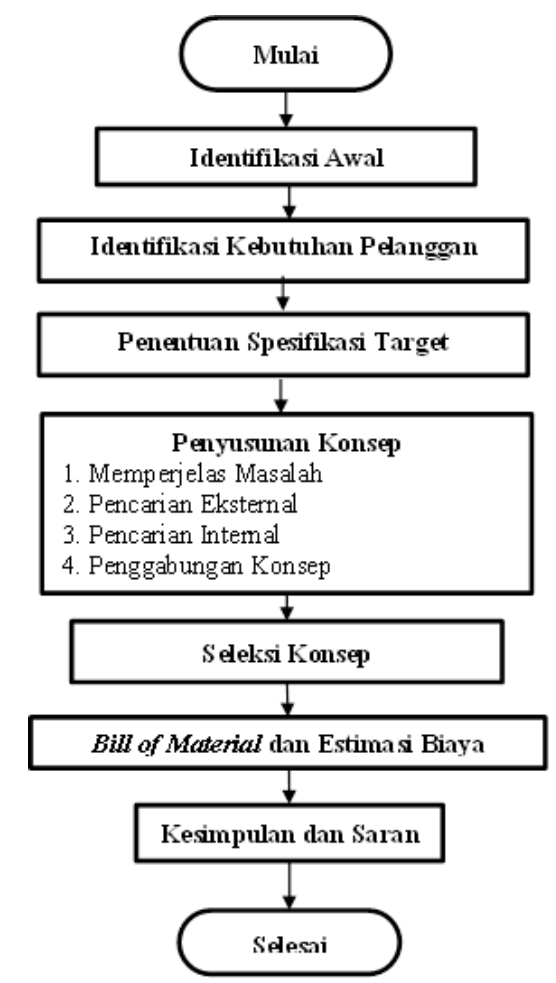

Gambar 1. Flowchart Metodologi Penelitian

Observasi dilakukan di seluruh stasiun kerja pada Departemen Weaving. Tujuan observasi adalah berupa dugaan sementara bahwa terdapat beberapa aktivitas kerja yang memiliki postur kerja yang tidak ergonomis dan berisiko. Oleh karena itu, dilakukan analisis level risiko sebagai identifikasi awal untuk memperkuat dugaan sementara yang diperoleh saat observasi.

Analisis level risiko dilakukan dengan menggunakan metode Rapid Entire Body Assessment (REBA) yang dapat menganalisis seluruh bagian tubuh pekerja melalui fokus terhadap keseluruhan postur tubuh yang diharapkan bisa mengurangi potensi terjadinya Musculoskletal Disorderspada tubuh pekerja (Sulaiman\&Sari, 2016). Langkah pertama yang dilakukan adalah pengambilan data gambar pekerja saat melakukan aktivitas pekerjaan. Langkah selanjutnya yaitu penentuan sudut tubuh dari pekerja pada tiap elemen kerja. Dan yang terakhir adalah menghitung skor REBA dari sudut tubuh yang terbentuk. Dari penilaian REBA ini dapat diketahui postur kerja dengan skor akhir REBA tertinggi. Perbaikan akan dilakukan pada aktivitas kerja tersebut dengan usulan desain alat bantu agar mengurangi risiko postur kerja operator.

Kemudian dilakukan perancangan alat bantu menggunakan proses pengembangan produk Ulrich dan Eppinger(Ulrich dan Eppinger, 2012). Tahap pertama adalah identifikasi kebutuhan pelanggan yang bertujuan memperoleh data opini dan harapan pengguna mengenai alat yang digunakan. Tahap ini dilakukan dengan cara personal interviews secara lisan dan bersifat informal kepada pekerja pada stasiun terpilih.

Tahap kedua adalah penentuan spesifikasi target. Tahap ini bertujuan agar pembuatan produk dapat memenuhi kebutuhan pelanggan dan dapat terukur secara kuantitatif. Spesifikasi target ditentukan dari hasil identifikasi kebutuhan melalui personal interview yang telah dilakukan. Hasil dari tahap ini adalah berupa tabel spesifikasi target yang berisi kebutuhan, metrik, dan satuan dari metric.

Tahap ketiga adalah tahap penyusunan konsep yang terdiri dari (1) tahap memperjelas masalah yaitu dekomposisi masalah menjadi sub-sub masalah; (2) pencarian eksternal yaitu pencarian solusi oleh pakar desain; (3) pencarian internal yaitu pencarian solusi yang berasal dari pemikiran dan pemunculan ide oleh peniliti pribadi; dan (4) penggabungan konsep menggunakan morphological chart, untuk menentukan beberapa alternatif solusi yang sesuai dengan tujuan alat tersebut dibuat.

Tahap keempat adalah tahap seleksi konsep. Tahap ini bertujuan untuk memilih konsep terbaik dengan mempertimbangkan nilai akhir dari masing-masing kriteria seleksi. Seleksi konsep dilakukan melalui dua tahap, yaitu penyaringan konsep dan ranking konsep. Setelah menemukan konsep terpilih berdasarkan seleksi konsep, langkah selanjutnya adalah penetapan dimensi alat bantu yang sesuai dengan kebutuhan pekerja. Pembuatan desain dan penetapan dimensi dilakukan menggunakan software Solidwork. Penetapan dimensi ini bertujuan agar alat bantu dapat berfungsi untuk mengurangi tingkat risiko berlebih, sehingga nyaman dan aman sesuai kaidah ergonomi. 
Tahap kelima adalah penyusunan bill of material dan estimasi biaya. Tahap ini bertujuan untuk memperjelas material yang digunakan dalam produk dan biaya yang dibutuhkan untuk memproduksi satu buah produk tersebut.

Dan tahap terakhir adalah penyusunan kesimpulan dan saran. Kesimpulan berisi ringkasan dari penelitian ini dan saran berisi saran bagi penelitian berikutnya.

\section{Hasil dan Pembahasan}

Pada bab ini menjelaskan identifikasi awal, identifikasi kebutuhan pelanggan, penentuan spesifikasi target, penyusunan konsep, dan seleksi konsep.

\section{- Identifikasi Awal}

Pada tahap ini dilakukan observasi lapangan dan analisis level risiko. Hasil dari tahap ini adalah berupa postur kerja pada elemen tertentu yang memiliki nilai level risiko tertinggi berdasarkan metode REBA.

a. Observasi

Pada tahap ini dilakukan pengamatan secara langsung keseluruhan proses di PT. Iskandar Indah Printing Textile Departemen Weaving. Departemen Weaving terdiri dari enam stasiun, yaitu stasiun warping, stasiun sheising (pengkanjian), stasiun recing (cucuk), stasiun palet (benang pakan), stasiun weaving (tenun), dan stasiun finishing (inspeksi). Hasil dari tahap observasi adalah dugaan sementara mengenai postur kerja pada stasiun tertentu yang terindikasi memiliki level risiko kerja yang tinggi. Rekap hasil observasi dapat dilihat pada Tabel 1.

Tabel 1. Hasil Observasi

\begin{tabular}{|c|l|}
\hline No & \multicolumn{1}{|c|}{ Hasil Observasi } \\
\hline 1 & $\begin{array}{l}\text { Semua stasiun masih menggunakan manual } \\
\text { material handling untuk beberapa aktivitas } \\
\text { tertentu }\end{array}$ \\
\hline 2 & $\begin{array}{l}\text { Stasiun finishing terindikasi memiliki level } \\
\text { risiko tinggi karena posturnya yang selalu } \\
\text { statis }\end{array}$ \\
\hline 3 & $\begin{array}{l}\text { Stasiun palet terindikasi memiliki level } \\
\text { risiko tinggi karena repetisi yang tinggi } \\
\text { setiap melakukan elemen kerja }\end{array}$ \\
\hline 4 & $\begin{array}{l}\text { Desain alat bantu pada stasiun palet perlu } \\
\text { pembaruan untuk mengurangi risiko kerja } \\
\text { berlebih bagi operator }\end{array}$ \\
\hline
\end{tabular}

\section{b. Analisis Level Risiko}

Untuk memperkuat dugaan hasil pengamatan, dilakukan analisis REBA pada seluruh elemen kerja.Hasil dari penilaian postur kerja menggunakan Rapid Entire Body Assessment (REBA) dari seluruh elemen kerja Departemen Weaving PT. Iskandar Indah Printing Textile disajikan dalam diagram sebaran berikut.

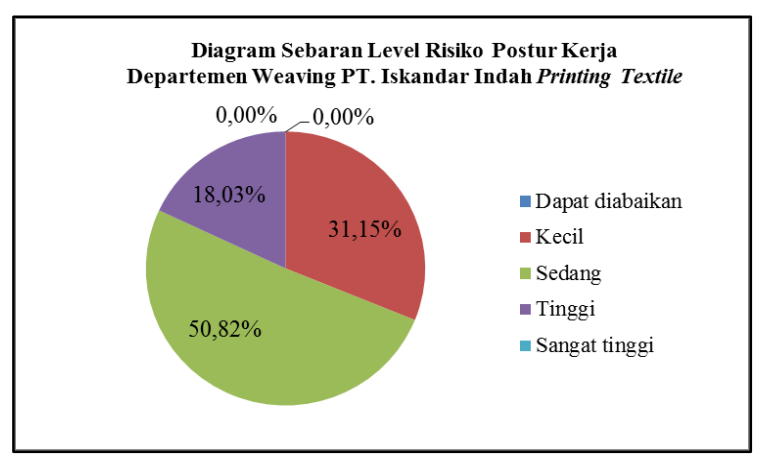

Gambar 2. Diagram Sebaran Level Risiko Postur

Dari diagram sebaran level risiko postur kerja diatas menunjukkan bahwa level risiko tinggi terjadi sebanyak $18,03 \%$. Berikut adalah elemen kerja pada stasiun palet.

Tabel 2.Elemen Kerja Stasiun Palet

\begin{tabular}{|l|l|c|c|c|c|}
\hline $\begin{array}{c}\text { AKTIVITAS } \\
\text { KERJA }\end{array}$ & $\begin{array}{c}\text { ELEMEN } \\
\text { KERJA }\end{array}$ & $\begin{array}{c}\text { SKOR } \\
\text { A }\end{array}$ & $\begin{array}{c}\text { SKOR } \\
\text { B }\end{array}$ & $\begin{array}{c}\text { SKOR } \\
\text { AKTIVITAS }\end{array}$ & $\begin{array}{c}\text { TOTAL } \\
\text { SKOR }\end{array}$ \\
\hline $\begin{array}{l}\text { Menyambung } \\
\text { benang pakan }\end{array}$ & $\begin{array}{l}\text { Mengambil } \\
\text { helai benang } \\
\text { pakan }\end{array}$ & 1 & 4 & 1 & 3 \\
\cline { 2 - 6 } & $\begin{array}{l}\text { Mengikat helai } \\
\text { benang pakan }\end{array}$ & 1 & 2 & 1 & 2 \\
\hline $\begin{array}{l}\text { Menggulung } \\
\text { benang } \\
\text { dengan mesin } \\
\text { palet }\end{array}$ & $\begin{array}{l}\text { Memasang } \\
\text { bobin pada } \\
\text { mesin palet }\end{array}$ & 3 & 3 & 1 & 4 \\
\cline { 2 - 6 } & $\begin{array}{l}\text { Menunggu } \\
\text { proses palet }\end{array}$ & 1 & 1 & 1 & 2 \\
\hline \multirow{2}{*}{$\begin{array}{l}\text { Mengambil } \\
\text { benang } \\
\text { selesai } \\
\text { digulung }\end{array}$} & $\begin{array}{l}\text { Mengambil } \\
\text { bobin pada } \\
\text { mesin palet }\end{array}$ & 7 & 5 & 1 & 10 \\
\cline { 2 - 6 } & $\begin{array}{l}\text { Meletakkan } \\
\text { bobin di } \\
\text { penyimpanan }\end{array}$ & 2 & 2 & 1 & 3 \\
\hline
\end{tabular}

Nilai tertinggi yaitu pada postur mengambil bobin pada mesin palet.Penilaian bagian tubuh dibagi menjadi dua bagian yaitu Grup A dan Grup B. Grup A meliputi bagian tubuh bagian leher, batang tubuh (punggung), dan kaki, menghasilkan nilai 7.Grup B meliputi bagian lengan atas, lengan bawah, dan pergelangan tangan, menghasilkan nilai 5. Serta skor aktivitas bernilai 1 untuk aktivitas pengulangan 
( $>4$ kali per menit). Sehingga, nilai akhir sebesar 10 dengan level risiko tinggi.

Elemen kerja ini memiliki level risiko yang tinggi disebabkan pekerja melakukan aktivitas mengambil bobin dengan posisi tubuh membungkuk karena bak penampung bobin yang telah selesai digulung berada di bawah atau mendekati permukaan lantai. Letak bak penampung bobin inilah yang menyebabkan skor REBA tinggi karena pekerja harus berdiri dan membungkuk dengan sudut tubuh mencapai $>60^{\circ}$, serta dilakukan berulang lebih dari 4 kali dalam semenit.

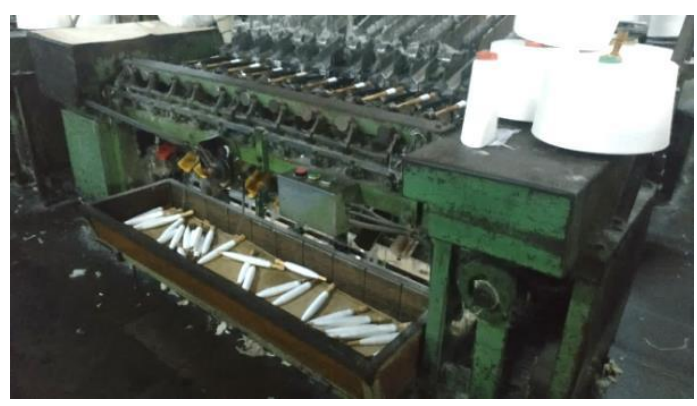

Gambar 3. Mesin Palet

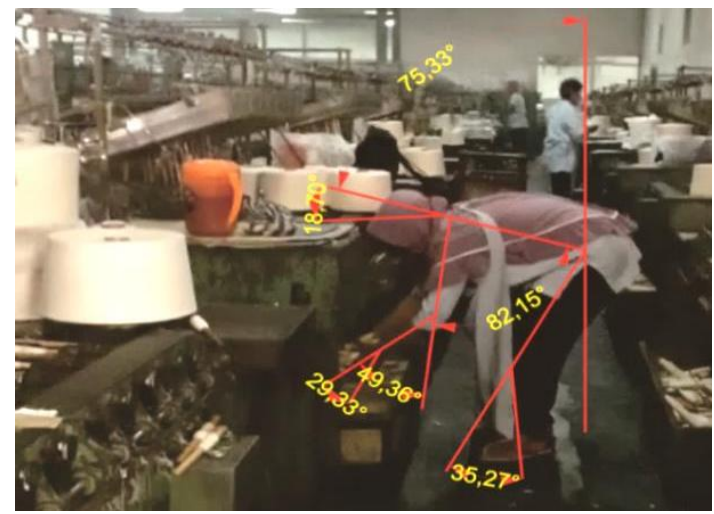

Gambar 4. Mengambil Bobin pada Mesin Palet

\section{- Identifikasi Kebutuhan Pelanggan}

Tahap ini dilakukan dengan personal interview.Interview dilakukan ke 5 dari 8 orang pekerja yang melakukan aktivitas mengambil bobin pada mesin palet. Sampel yang diambil berjumlah 5 orang, berdasarkan penelitian terdahulu pada buku Ulrich dan Eppinger,melakukan wawancara terhadap 5 orang akan mendapatkan informasi identifikasi kebutuhan sebanyak 80\% (Ulrich \& Eppinger, 2012, hlm. 77).Berikut adalah daftar pertanyaan untuk mendapatkan informasi kebutuhan pelanggan.
Tabel 3. Daftar Pertanyaan

\begin{tabular}{|c|l|}
\hline No & \multicolumn{1}{|c|}{ Daftar Pertanyaan } \\
\hline 1 & $\begin{array}{l}\text { Apakah posisi bak penampung } \\
\text { menimbulkan kelelahan? }\end{array}$ \\
\hline 2 & $\begin{array}{l}\text { Berapa kali Anda melakukan pengambilan } \\
\text { bobin? Tiap berapa menit? }\end{array}$ \\
\hline 3 & $\begin{array}{l}\text { Apakah memungkinkan memindahkan } \\
\text { bobin dengan mengangkat bak } \\
\text { penampungnya? }\end{array}$ \\
\hline 4 & $\begin{array}{l}\text { Apakah Anda membutuhkan inovasi } \\
\text { perbaikan atau usulan alat bantu baru untuk } \\
\text { mempermudah pengambilan bobin? }\end{array}$ \\
\hline
\end{tabular}

Tabel 4. Rekap Hasil Interview

\begin{tabular}{|c|l|}
\hline No & \multicolumn{1}{|c|}{ Hasil Interview } \\
\hline 1 & $\begin{array}{l}\text { Tidak ada alat bantu untuk mengambil } \\
\text { bobin dari bak penampung }\end{array}$ \\
\hline 2 & $\begin{array}{l}\text { Bak penampung terlalu pendek, sehingga } \\
\text { menyebabkan sakit punggung }\end{array}$ \\
\hline 3 & $\begin{array}{l}\text { Bak penampung memiliki kapasitas yang } \\
\text { sedikit }\end{array}$ \\
\hline 4 & $\begin{array}{l}\text { Material yang digunakan untuk bak } \\
\text { penampung berat }\end{array}$ \\
\hline
\end{tabular}

- Penentuan Spesifikasi Target

Bagian ini menjelaskan spesifikasi target yang ditentukan untuk memperjelas tujuan dan arah produk tersebut dibuat. Spesifikasi ini dapat berupa spesifikasi fisik, maupun spesifikasi teknis produk. Berikut adalah tabel spesifikasi target dari produk.

Tabel 5. Spesifikasi Target

\begin{tabular}{|c|c|c|c|}
\hline No & Kebutuhan & Metrik & Satuan \\
\hline 1 & $\begin{array}{l}\text { Memanfaatkan } \\
\text { ruang bawah } \\
\text { mesin }\end{array}$ & $\begin{array}{l}\text { Tinggi bak } \\
\text { penampung }\end{array}$ & $\mathrm{Cm}$ \\
\hline 2 & Mudah dijangkau & $\begin{array}{l}\text { Letak } \\
\text { Handle }\end{array}$ & $\mathrm{Cm}$ \\
\hline 3 & $\begin{array}{l}\text { Kapasitas } \\
\text { diperbesar }\end{array}$ & Volume bak & $\mathrm{cm}^{3}$ \\
\hline 4 & $\begin{array}{l}\text { Bisa dipindahkan } \\
\text { / diangkat }\end{array}$ & $\begin{array}{l}\text { Material } \\
\text { ringan }\end{array}$ & gram \\
\hline 5 & Produk awet & $\begin{array}{l}\text { Material } \\
\text { tahan lama }\end{array}$ & - \\
\hline 6 & $\begin{array}{l}\text { Penggunaan } \\
\text { mudah }\end{array}$ & $\begin{array}{l}\text { Mekanisme } \\
\text { sederhana }\end{array}$ & - \\
\hline 7 & $\begin{array}{l}\text { Mengurangi risiko } \\
\text { postur }\end{array}$ & $\begin{array}{l}\text { Sudut } \\
\text { batang tubuh }\end{array}$ & o \\
\hline
\end{tabular}

\section{- Penyusunan Konsep}

Tujuan penyusunan konsep adalah menggali lebih jauh area konsep-konsep 
produk yang sesuai dengan kebutuhan konsumen.Tahap ini terdiri dari empat tahap, yaitu tahap memperjelas masalah, pencarian eksternal, pencarian internal, dan penggabungan konsep.

\section{Memperjelas Masalah}

Tahap ini bertujuan agar lebih mudah menemukan akar masalah dengan melakukan dekomposisi menjadi sub-sub masalah. Daftar masalah yang akan di dekomposisi adalah masalah yang ditemukan pada hasil personal interview.

Tabel 6.Hasil Dekomposisi Masalah

\begin{tabular}{|l|l|}
\hline \multicolumn{1}{|c|}{ Masalah } & \multicolumn{1}{c|}{ Sub Masalah } \\
\hline $\begin{array}{l}\text { Tidak ada alat bantu } \\
\text { untuk mengambil bobin } \\
\text { dari bak penampung }\end{array}$ & $\begin{array}{l}\text { Bobin jatuh ke bagian } \\
\text { bawah mesin secara } \\
\text { otomatis dan } \\
\text { ditampung dengan bak }\end{array}$ \\
\hline $\begin{array}{l}\text { Bak penampung terlalu } \\
\text { pendek, sehingga } \\
\text { menyebabkan sakit } \\
\text { punggung }\end{array}$ & $\begin{array}{l}\text { Letak bak penampung } \\
\text { yang terlalu rendah } \\
\text { Bak penampung } \\
\text { diletakkan bawah } \\
\text { mesin }\end{array}$ \\
\hline $\begin{array}{l}\text { Bak penampung dibuat } \\
\text { hanya bertujuan agar } \\
\text { bobin tidak tercecer dari } \\
\text { mesin }\end{array}$ & $\begin{array}{l}\text { Bak penampung tidak } \\
\text { memudahkan operator } \\
\text { dalam mengambil } \\
\text { bobin }\end{array}$ \\
\hline $\begin{array}{l}\text { Material yang digunakan } \\
\text { berat }\end{array}$ & $\begin{array}{l}\text { Bak penampung } \\
\text { berukuran besar (satu } \\
\text { bak per mesin) }\end{array}$ \\
\hline
\end{tabular}

\section{Pencarian Eksternal}

Pencarian eksternal bertujuan untuk menemukan pemecahan keseluruhan masalah dan submasalah yang ditemukan selama langkah memperjelas masalah hasil diskusi langsung dengan pakar desain.

Tabel 7. Hasil Pencarian Eksternal

\begin{tabular}{|l|l|}
\hline \multicolumn{1}{|c|}{ Sub Masalah } & \multicolumn{1}{c|}{ Solusi } \\
\hline $\begin{array}{l}\text { Bobin jatuh ke bagian } \\
\text { bawah mesin secara } \\
\text { otomatis dan } \\
\text { ditampung dengan bak }\end{array}$ & $\begin{array}{l}\text { Memodifikasi desain } \\
\text { bak penampung agar } \\
\text { memudahkan dalam } \\
\text { mengambil bobin }\end{array}$ \\
\hline $\begin{array}{l}\text { Letak bak penampung } \\
\text { yang terlalu rendah } \\
\begin{array}{l}\text { Bak penampung } \\
\text { diletakkan bawah } \\
\text { mesin }\end{array}\end{array}$ & $\begin{array}{l}\text { Membuat alat bantu } \\
\text { dengan ketinggian } \\
\text { tertentu untuk } \\
\text { mempermudah } \\
\text { pengambilan bobin }\end{array}$ \\
\hline
\end{tabular}

\begin{tabular}{|l|l|}
\hline $\begin{array}{l}\text { Bak penampung tidak } \\
\text { memudahkan operator } \\
\text { dalam mengambil } \\
\text { bobin }\end{array}$ & $\begin{array}{l}\text { Memodifikasi desain } \\
\text { dengan mekanisme } \\
\text { tertentu sesuai } \\
\text { kebutuhan }\end{array}$ \\
\hline $\begin{array}{l}\text { Bak penampung } \\
\text { berukuran besar (satu } \\
\text { bak per mesin) }\end{array}$ & $\begin{array}{l}\text { Dibuat partisi pada bak } \\
\text { penampung } \\
\text { Menggunakan material } \\
\text { sesuai kebutuhan }\end{array}$ \\
\hline
\end{tabular}

\section{Pencarian Internal}

Pencarian internal bertujuan untuk menemukan pemecahan masalah yang telah ditemukan pada tahap sebelumnya. Tahap ini dilakukan dengan cara melibatkan pemikiran dan pemunculan ide baru secara individu oleh peneliti.

Tabel 8.Hasil Pencarian Internal

\begin{tabular}{|l|l|}
\hline \multicolumn{1}{|c|}{ Sub Masalah } & \multicolumn{1}{c|}{ Solusi } \\
\hline $\begin{array}{l}\text { Bobin jatuh ke } \\
\text { bagian bawah mesin } \\
\text { secara otomatis dan } \\
\text { ditampung dengan } \\
\text { bak }\end{array}$ & $\begin{array}{l}\text { Bak penampung dibuat } \\
\text { dengan alas penampang } \\
\text { yang tinggi, sehingga } \\
\text { lebih mudah dijangkau }\end{array}$ \\
\hline $\begin{array}{l}\text { Letak bak } \\
\text { penampung yang } \\
\text { terlalu rendah } \\
\text { Bak penampung } \\
\text { diletakkan bawah } \\
\text { mesin }\end{array}$ & $\begin{array}{l}\text { Memodifikasi bak } \\
\text { penampung dengan } \\
\text { memaksimalkan ruang } \\
\text { pada bagian bawah } \\
\text { mesin }\end{array}$ \\
\hline $\begin{array}{l}\text { Bak penampung } \\
\text { tidak memudahkan } \\
\text { operator dalam } \\
\text { mengambil bobin }\end{array}$ & $\begin{array}{l}\text { Bak penampung } \\
\text { dimodifikasi dengan } \\
\text { ketinggian tertentu agar } \\
\text { memudahkan operator } \\
\text { dalam mengambil bobin }\end{array}$ \\
\hline $\begin{array}{l}\text { Bak penampung } \\
\text { berukuran besar (satu } \\
\text { bak per mesin) }\end{array}$ & $\begin{array}{l}\text { Bak penampung dibuat } \\
\text { diperbanyak partisi dan } \\
\text { menggunakan material } \\
\text { yang ringan }\end{array}$ \\
\hline
\end{tabular}

\section{Penggabungan Konsep}

Pada tahap ini dilakukan mengidentifikasi kombinasi yang menjadi alternatif pilihan perancangan alat bantu menggunakan morphological chart. Pada bagian kiri berisi aspek-aspek yang diperlukan atau disebut juga subfungsi, sedangkan bagian kanan berisi mekanisme yang dapat memenuhi subfungsi. 


\begin{tabular}{|c|c|c|c|c|}
\hline \multirow{2}{*}{ No } & \multirow{2}{*}{ Subfungsi } & \multicolumn{3}{|c|}{ Solusi } \\
\hline & & $\bar{I}$ & III & IIII \\
\hline 1 & Sistem & $\begin{array}{r}\text { Manual } \\
Q\end{array}$ & Semi Otomatis & \\
\hline 2 & Mekanisme & Crank & tinkage & Linkage \\
\hline 3 & $\begin{array}{l}\text { Gerakan } \\
\text { Positioning }\end{array}$ & Naik & balik & \\
\hline 4 & $\begin{array}{l}\text { Handling } \\
\text { Operator }\end{array}$ & Tuas & Pedalkaki & \\
\hline 5 & $\begin{array}{l}\text { Profil } \\
\text { Rangka }\end{array}$ & $\begin{array}{l}\text { Hollo } \\
\text { Pipe }\end{array}$ & Round Pipe & \\
\hline 6 & $\begin{array}{l}\text { Material } \\
\text { Rangka }\end{array}$ & Besi & Kayu & \\
\hline 7 & $\begin{array}{l}\text { Partisi Bak } \\
\text { Penampung }\end{array}$ & $2 \mathrm{pcs} / \mathrm{m}$ & $1 \mathrm{pc} /$ mesin & \\
\hline
\end{tabular}

Gambar 5. Morphological Chart

Terdapat tiga alternatif konsep yang dibagi berdasarkan warna, yaitu alternatif konsep I dengan warna biru, alternatif konsep II dengan warna merah, dan alternatif konsep III dengan warna hijau.

Berikut adalah hasil desain dari tiap-tiap alternatif yang dihasilkan.

a. Alternatif konsep desain I

Alternatif konsep desain yang pertama adalah bak penampung dengan sistem penggerak manual, mekanisme berupa crank linkage yang bergerak secara vertikal. Crank Linkage adalah sistem pengangkat dengan mekanisme linkage yang dioperasikan dengan cara ditarik menggunakan tuas / Handle. Ini digunakan untuk mengubah gerakan melingkar poros menjadi gerakan bolak-balik.Bak penampung menggunakan rangka berupa hollow square pipe dengan material besi.Konsep pertama ini memiliki partisi bak penampung sebanyak 2 pcs per mesin.

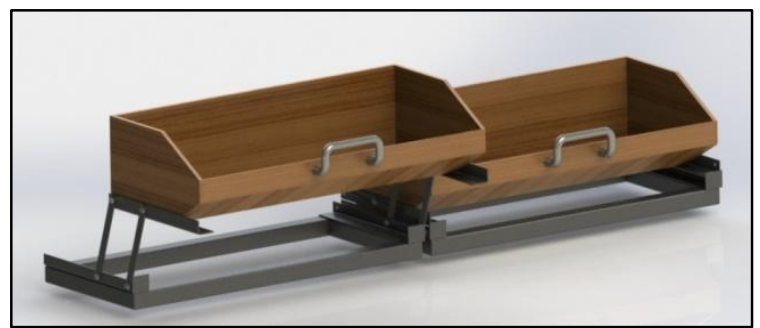

Gambar 6. Konsep Desain I b. Alternatif konsep desain II

Alternatif konsep desain yang kedua adalah bak penampung dengan sistem penggerak manual, mekanisme berupa path linkage yang bergerak secara vertikal dan terdapat pembalik.Path Linkage adalah sistem pengangkat dengan mekanisme linear path atau jalur untuk mengangkat dan membalikkan benda.Operator dapat mengoperasikannya dengan menggunakan tuas / Handle.Bak penampung menggunakan rangka berupa hollow square pipe dengan material besi.Konsep kedua ini memiliki partisi bak penampung sebanyak 2 pcs per mesin.

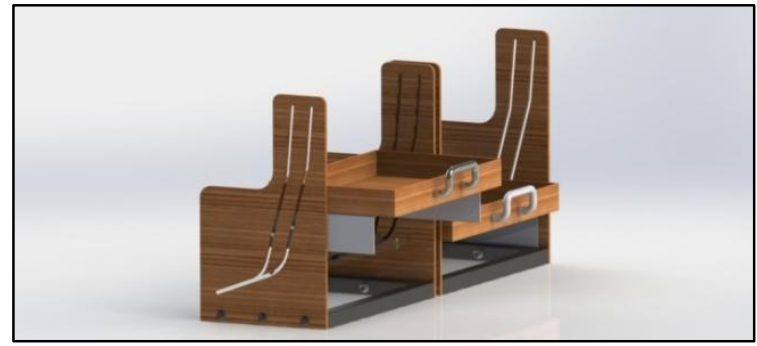

Gambar 7. Konsep Desain II

\section{c. Alternatif konsep desain III}

Alternatif konsep desain yang ketiga adalah bak penampung dengan sistem penggerak semi otomatis, mekanisme berupa hydraulic linkage yang bergerak secara vertikal. Hydraulic Linkageadalah sistem pengangkat menggunakan tenaga hidrolik, dan dapat dioperasikan dengan menggunakan pedal kaki. Bak penampung menggunakan rangka berupa hollow square pipe dengan material besi. Konsep ketiga ini memiliki partisi bak penampung sebanyak $1 \mathrm{pc}$ per mesin.

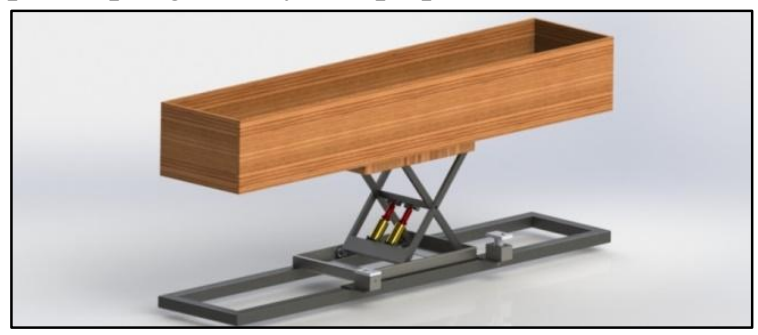

Gambar 8. Konsep Desain III

\section{- Seleksi Konsep}

Tahap ini bertujuan untuk memilih konsep terbaik dengan mempertimbangkan nilai akhir dari masing-masing kriteria seleksi, dengan menggunakan metode Pugh. Kriteria seleksi yang digunakan dalam penyaringan konsep 
adalah dalam segi biaya pembuatan alat bantu, kemudahan dalam penggunaan, kapasitas alat bantu, dan kekuatan material.

Nilai-nilai yang digunakan dalam perhitungan nilai konsep adalah nilai "sama" (0), "lebih baik" (+), atau "lebih buruk" (-) yang diletakkan pada tiap sel sebagai perbandingan. Nilai nol diberikan apabila alternatif konsep usulan sama baiknya dengan desain yang sudah ada. Nilai positif diberikan apabila alternatif konsep lebih baik dari konsep yang sudah ada, sedangkan nilai negatif diberikan apabila alternatif konsep lebih buruk dari konsep yang sudah ada.Penilaian ini dilakukan peneliti dengan melakukan diskusi bersama pakar desain.

Tabel 9.Matriks Seleksi Konsep

\begin{tabular}{|c|l|c|c|c|}
\hline \multirow{2}{*}{ No } & \multicolumn{1}{|c|}{$\begin{array}{c}\text { Kriteria } \\
\text { Seleksi }\end{array}$} & $\begin{array}{c}\text { Alternatif Konsep } \\
\text { I }\end{array}$ & $\begin{array}{c}\text { Konsep } \\
\text { II }\end{array}$ & $\begin{array}{c}\text { Konsep } \\
\text { III }\end{array}$ \\
\cline { 3 - 5 } & $\begin{array}{l}\text { Kemudahan } \\
\text { penggunaan } \\
\text { mekanisme }\end{array}$ & + & + & + \\
\hline 3 & $\begin{array}{l}\text { Kemudahan } \\
\text { handling }\end{array}$ & + & + & + \\
\hline & $\begin{array}{l}\text { Kemudahan } \\
\text { memindahkan } \\
\text { bobin }\end{array}$ & 0 & + & 0 \\
\hline 4 & $\begin{array}{l}\text { Durability } \\
\text { mekanisme }\end{array}$ & - & + & + \\
\hline 5 & $\begin{array}{l}\text { Biaya } \\
\text { mekanisme }\end{array}$ & 0 & + & - \\
\hline \multicolumn{2}{|l}{ Jumlah (+) } & 2 & 5 & 3 \\
\hline Jumlah (0) & 0 & 0 & 1 \\
\hline \multicolumn{2}{|l|}{ Jumlah (-) } & 1 & 0 & 1 \\
\hline Nilai Akhir & 1 & 5 & 2 \\
\hline Peringkat & 3 & 1 & 2 \\
\hline
\end{tabular}

Alternatif konsep yang terpilih adalah konsep II dengan nilai pada kriteria seleksi sebanyak 5.Pada konsep kedua ini, diharapkan desain mempermudah pengoperasikan oleh operator, serta bak yang dapat berbalik $90^{\circ}$ memudahkan operator dalam mengambil bobin. Material bak berupa kayu, dan mekanisme path linkage memiliki harga yang terjangkau, sehingga akan sangat memungkinkan untuk direalisasikan secara massal.

\section{Penentuan Dimensi Alternatif Terpilih}

Penentuan dimensi alternatif konsep yang terpilih yaitu konsep II, ditentukan dengan memaksimalkan ruang yang ada berdasarkan ruang kosong pada bagian bawah mesin.Hal tersebut disebabkan karena bobin secara otomatis jatuh ke bagian bawah mesin, dan ruang kosongtersebut memiliki ruang yang terbatas, sehingga dimensi bak penampung perlu disesuaikan. Ruang bagian bawah mesin yang dapat dimanfaatkan memiliki dimensi panjang $130 \mathrm{~cm}$, lebar $36 \mathrm{~cm}$, dan tinggi 40 $\mathrm{cm}$. Dimensi tersebut yang akan menjadi dasar untuk penentuan dimensi bak penampung.

Berikut adalah dimensi dan gambar dari tiap komponen bak penampung terpilih.

\section{Box Hooper}

$\begin{array}{ll}\text { Panjang Box Hooper } & =60,62 \mathrm{~cm} \\ \text { Lebar Box Hooper } & =41,07 \mathrm{~cm} \\ \text { Tinggi Box Hooper } & =10,03 \mathrm{~cm}\end{array}$

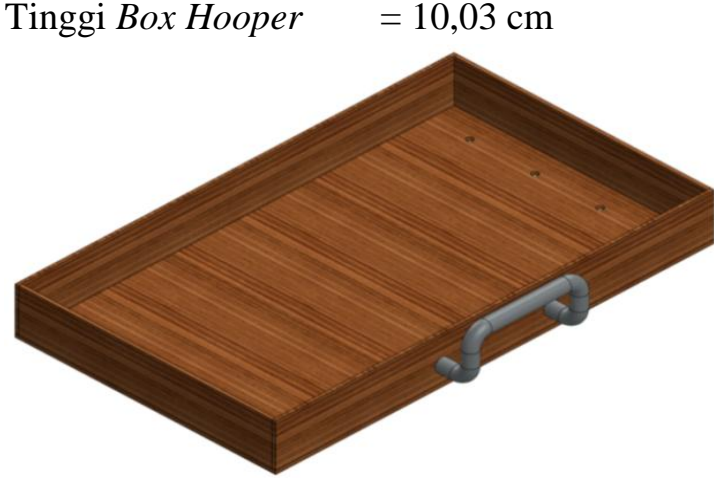

Gambar 9. Box Hooper

\section{Assy Lifter Left \& Right}

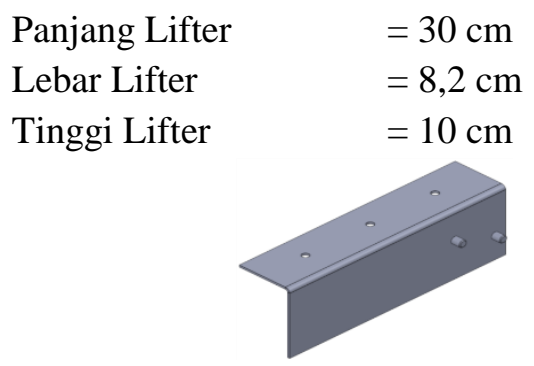

Gambar 10. AssyLifter

\section{Pin Guidance}

Panjang Pin Guidance $=1,5 \mathrm{~cm}$

Diameter Pin Guidance $=1 \mathrm{~cm}$

Chamfer Pin Guidance $=1 \mathrm{~mm}$

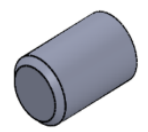

Gambar 11. Pin Guidance 
MATRIK : Jurnal Manajemen \& Teknik Industri - Produksi Volume XX, No.2, Maret 2020, Halaman 91-102

\section{Assy Frame}

Panjang Frame

$=60,62 \mathrm{~cm}$

Lebar Frame

$$
=36 \mathrm{~cm}
$$

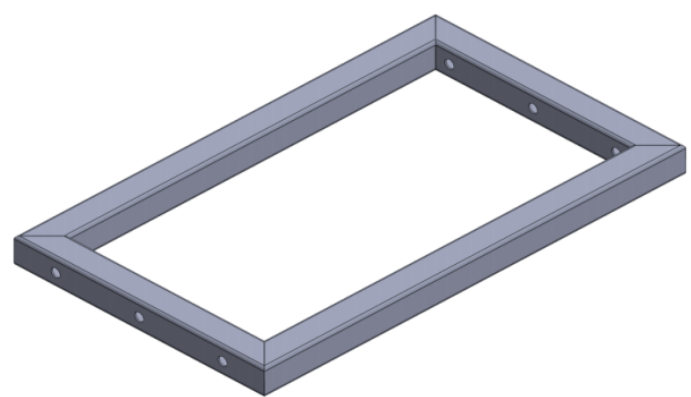

Gambar 12. Assy Frame

\section{Handle}

Panjang Handle

$$
\begin{aligned}
& =16,91 \mathrm{~cm} \\
& =3 / 4 \text { inci } \\
& =4,95 \mathrm{~cm} \\
& =7,91 \mathrm{~cm}
\end{aligned}
$$

Tinggi Handle

Lebar Handle

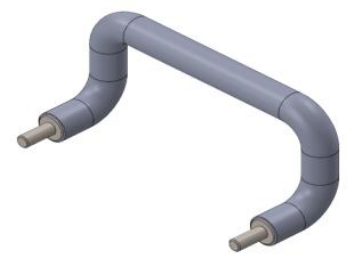

Gambar 13. Handle

\section{Komponen Tambahan}

Berikut adalah komponen tambahan yang digunakan untuk merakit bak penampung, terdiri dari Nut M8 dan Hexbolt M8x20, serta Nut M12 dan Hexbolt M12x60.

\section{Gambar 14.Nut M8}

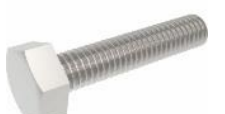

Gambar 15. Hexbolt M8x20

Gambar 16. Nut M12

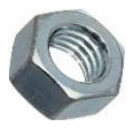

p-ISSN: 1693-5128, e-ISSN : 2621-8933 doi: $10.350587 /$ Matrik v20i1.1137

\section{Gambar 17. Hexbolt M12x60}

\section{Bill of Material dan Estimasi Biaya}

Pada bagian ini menjelaskan mengenai Bill of Material yang memuat keseluruhan komponen yang diperlukan untuk membuat bak penampung usulan beserta material yang

digunakan. Bill of Material (BOM) dapat dilihat pada Gambar 18.

Kemudian setelah penentuan BOM yang telah disusun, dilakukan penentuan estimasi biaya untuk memproduksi tiap bak penampung, berdasarkan kebutuhan material dan spesifikasi yang telah ditentukan.Estimasi biaya pembuatan produk dapat dilihat pada Tabel 10.

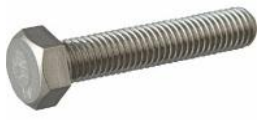




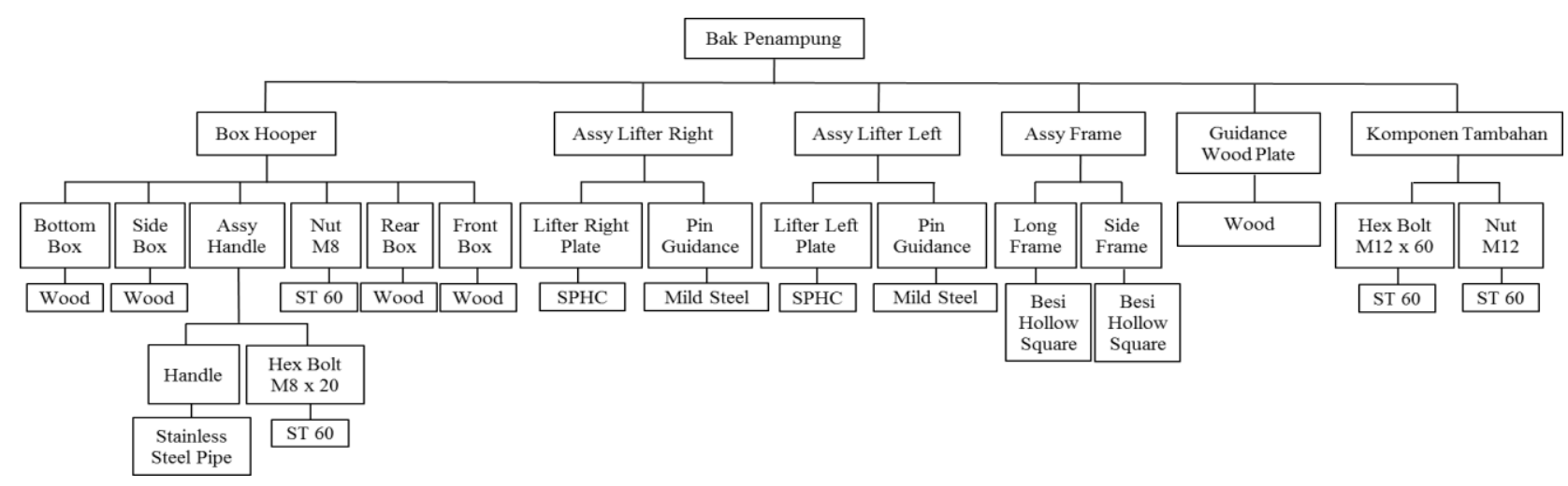

Gambar 18. Bill of Material

Tabel 10. Estimasi Biaya

\begin{tabular}{|c|c|c|c|c|c|}
\hline No & Part & Material & Harga & Kebutuhan & Total Biaya \\
\hline 1 & Bottom Box & \multirow[b]{4}{*}{$\begin{array}{c}\text { Wood } \\
(\mathrm{t}=5 \mathrm{~mm})\end{array}$} & \multirow[b]{4}{*}{$\mathrm{Rp} 20,00 / \mathrm{cm}^{2}$} & \multirow{4}{*}{$\begin{array}{l}2 \text { buah } x\left(2.182,32 \mathrm{~cm}^{2}\right)= \\
4.364,64 \mathrm{~cm}^{2} \sim 4.500 \mathrm{~cm}^{2} \\
4 \text { buah } x\left(227,5 \mathrm{~cm}^{2}\right)=910 \mathrm{~cm}^{2} \\
2 \text { buah } x\left(394,03 \mathrm{~cm}^{2}\right)=788,06 \\
\mathrm{~cm}^{2} \sim 800 \mathrm{~cm}^{2} \\
2 \text { buah } \times\left(394,03 \mathrm{~cm}^{2}\right)=788,06 \\
\mathrm{~cm}^{2} \sim 800 \mathrm{~cm}^{2} \\
\text { Total Kebutuhan }=7.010 \mathrm{~cm}^{2}\end{array}$} & \multirow[b]{4}{*}{ Rp $140.200,00$} \\
\hline 2 & Side Box & & & & \\
\hline 3 & Rear Box & & & & \\
\hline 4 & Front Box & & & & \\
\hline 5 & Lifter Plate Right & \multirow{2}{*}{$\begin{array}{c}\text { SPHC } \\
(\mathrm{t}=3 \mathrm{~mm})\end{array}$} & \multirow[t]{2}{*}{$\mathrm{Rp} 26,00 / \mathrm{cm}^{2}$} & 2 buah $x\left(510 \mathrm{~cm}^{2}\right)=1.020 \mathrm{~cm}^{2}$ & \multirow[b]{2}{*}{ Rp 53.000,00 } \\
\hline 6 & Lifter Plate Left & & & $\begin{array}{l}2 \text { buah } x\left(510 \mathrm{~cm}^{2}\right)=1.020 \mathrm{~cm}^{2} \\
\text { Total kebutuhan }=2.040 \mathrm{~cm}^{2}\end{array}$ & \\
\hline 7 & Pin Guidance & $\begin{array}{l}\text { Mild Steel } \\
\text { Round Bar }(\mathrm{d} \\
=10 \mathrm{~mm})\end{array}$ & $\begin{array}{l}\mathrm{Rp} 200,00 / \\
\mathrm{Cm}\end{array}$ & $8 \times(1,5 \mathrm{~cm})=12 \mathrm{~cm}$ & $\operatorname{Rp} 2.400,00$ \\
\hline 8 & Handle & $\begin{array}{l}\text { Stainless Steel } \\
\text { Pipe }(\mathrm{d}=3 / 4 \\
\text { inch })\end{array}$ & $\begin{array}{l}\mathrm{Rp} 7.000,00 / \\
20 \mathrm{~cm}\end{array}$ & $2 \times(43 \mathrm{~cm})=86 \mathrm{~cm}$ & Rp 35.000,00 \\
\hline 9 & Long Frame & \multirow{2}{*}{$\begin{array}{l}\text { Besi Hollow } \\
\text { Square } \\
(40 \mathrm{~mm} \times 40 \\
\mathrm{mm})\end{array}$} & \multirow{2}{*}{$\begin{array}{l}\text { Rp18.500,0/ } \\
4 \mathrm{~m}\end{array}$} & \multirow{2}{*}{$\begin{array}{l}4 \times(60,62 \mathrm{~cm})=242,48 \mathrm{~cm} \\
4 \times(36 \mathrm{~cm})=144 \mathrm{~cm} \\
\text { Total kebutuhan }=386,48 \mathrm{~cm}^{2}\end{array}$} & \multirow[b]{2}{*}{ Rp $18.500,00$} \\
\hline 10 & Side Frame & & & & \\
\hline 11 & $\begin{array}{l}\text { Guidance Wood } \\
\text { Plate }\end{array}$ & $\begin{array}{r}\text { Wood } \\
(\mathrm{t}=10 \mathrm{~mm})\end{array}$ & $\begin{array}{l}\text { Rp100.000/ } \\
\text { lembar }\end{array}$ & $4 \times\left(2.160 \mathrm{~cm}^{2}\right)=8.640 \mathrm{~cm}^{2}$ & Rp100.000,00 \\
\hline 12 & Nut M8 & \multirow[t]{2}{*}{ ST 60} & \multirow{2}{*}{$\begin{array}{l}\text { Rp400,00/ } \\
\text { pasang }\end{array}$} & \multirow[t]{2}{*}{$4 \times 3$ pasang $=12$ pasang } & \multirow{2}{*}{ Rp 2.400,00 } \\
\hline 13 & Hexbolt M8x20 & & & & \\
\hline 14 & Nut M12 & \multirow[t]{2}{*}{ ST 60} & \multirow{2}{*}{$\begin{array}{l}\text { Rp1.300,00/ } \\
\text { pasang }\end{array}$} & \multirow[t]{2}{*}{$4 \times 3$ pasang $=12$ pasang } & \multirow{2}{*}{ Rp 15.600,00 } \\
\hline 15 & Hexbolt M12x60 & & & & \\
\hline \multicolumn{5}{|c|}{ Biaya Pekerja } & Rp 500.000,00 \\
\hline \multicolumn{5}{|c|}{ TOTAL BIAYA } & Rp 867.100,00 \\
\hline
\end{tabular}

(Sumber : tokopedia.com) 


\section{Kesimpulan dan Saran}

Penelitian ini bertujuan untuk mengurangi level risiko tinggi yang ditemukan pada observasi awal, yaitu postur mengambil bobin pada mesin palet REBA yaitu 10 dengan tindakan segera dilakukan perbaikan. Diusulkan sebuah perancangan perbaikan bak penampung untuk mengurangi level risiko pada postur pekerja.

Bak penampung yang diusulkan sistem penggerak manual, mekanisme berupa path linkage yang bergerak secara vertikal dan terdapat pembalik. Path Linkage adalah sistem pengangkat dengan mekanisme linear path atau jalur untuk mengangkat dan membalikkan benda. Operator dapat mengoperasikannya dengan menggunakan tuas / Handle. Bak penampung menggunakan rangka berupa hollow square pipe dengan material besi. Konsep kedua ini memiliki partisi bak penampung sebanyak 2 pcs per mesin. Desain ini mudah dioperasikan oleh operator, serta bak yang dapat berbalik 90o memudahkan operator dalam mengambil bobin.

Untuk penelitian berikutnya, diharapkan dapat melanjutkan tahap dari penelitian ini, yaitu membuat prototype serta memasarkannya. Saran bagi perusahaan yaitu menerapkan usulan perancangan produk agar mengurangi risiko postur kerja bagi operator sehingga pekerja dapat nyaman dan meningkatkan produktivitas.

\section{Daftar Pustaka}

[1] Astuti, R.D dan Irwan Iftadi. 2016. Analisis dan Perancangan Sistem Kerja. Deepublish: Yogyakarta.

[2] Ayoub, M. M. and Dampsey, P. G. 1999. The Psychophysical Approach to Material Handling Task Design.Ergonomic Vol. 42. No. 1, pp: $17-31$.

[3] Kementrian Perindustrian Republik Indonesia. 2017. Siaran Pers: Jakarta.

Diaksesdari:
https://kemenperin.go.id/artikel/17776/Su mbang-Devisa-USD-12-Miliar,-IndustriTPT-Ditargetkan-Tumbuh

[4] Kurnianto, Rian Yuni., dan Mulyono. 2014. Gambaran Postur Kerja Dan Resiko Terjadinya Muskuloskeletal Pada Pekerja Bagian Welding Di Area Workshop Bay 4.2 PT. Alstom Power Energy Systems Indonesia. The Indonesian Journal of Occupational Safety , Health and Environment, Vol. 1.

[5] Muslimah, Etika., Indah Pratiwi, dan Fariza Rafsanjani. 2006. Analisis Manual Material Handling Menggunakan NIOSH Equation. Jurnal Ilmiah Teknik Industri, Vol. 5 (2) 53-60.

[6] Novianti, Diah M., dan Tanjung S. 2016. Analisis Perbaikan Postur Kerja Operator Pada Proses Pembuatan Pipa Untuk Mengurangi Musculoskeletal Disorders Dengan Menggunakan Metode RULA. Seminar Nasional Sains dan Teknologi 2016.

[7] Sedarmayanti, 1996. Ergonomi untuk Produktivitas Kerja. Mandar Maju: Jakarta

[8] Soedirman. 1989. Penyakit Akibat Kerja dan Penyakit yang Berhubungan dengan Pekerjaan. Jakarta: Universitas Indonesia

[9] Sulaiman, Fahmi dan Yossi Purnama Sari. 2016. Analisis Postur Kerja Pekerja Proses Pengesahan Batu Akik Dengan Menggunakan Metode REBA. Jurnal Teknovasi Vol. 3 No 1

[10] Ulrich, Karl T and Steven D Eppinger, 2012. Perancangan dan Pengembangan Produk, Terjemahan oleh Nora Azmi dan Iveline Anne Marie. Salemba Teknika, Jakarta

[11] Yuwono Rio, dan Ferida Yuamita. 2015. Analisa Faktor K3 dan Ergonomi Terhadap Fasilitas Pusat Kesehatan Universitas Untuk Mengukur Kepuasan Pasien. Jurnal Ilmiah Teknik Industri, Vol. 14. Universitas Teknologi Yogyakarta: Yogyakarta. 
Nathania/MATRIK. Vol.XX, No.2, Maret 2020, Halaman 91-102 